Obstetricia

\section{SEQÜÊNCIA DE ALTERAÇ̃̃ES DO DOPPLER NA CIRCULAÇÃO FETAL CENTRAL E PERIFÉRICA}

A desnutrição intra-uterina, traduzida pelo nascimento de recém-nascidos ( $R N$ ) pequenos para a idade gestacional, os famosos PIGs, um paradigma da insuficiência placentária, constitui tópico de grande relevância obstétrica e de infindáveis pesquisas à busca de sua etiologia. Essas pesquisas são motivadas também pela alta incidência, tendo média de $15 \%$ na população em geral'. Na assistência pré-natal contemporânea, é impossível oferecer cuidados adequados sem o recurso de propedêutica obstétrica com tecnologia de ponta, em situações de grave comprometimento fetal. Outrora um requinte, modernamente essencial, a dopplervelocimetria dos compartimentos materno e fetal da placenta ${ }^{2}$ e dos vasos centrais e periféricos fetais é imprescindível para a eleição do momento ideal para a interrupção da gestação com a intenção de se oferecer um desfecho exitoso. Com esse exame, de máxima evolução técnica e precisão, consegue-se graduar o quanto os fetos são subjugados às potencialmente desconhecidas injúrias. Estas, decorrentes da carência de transferência de oxigênio por períodos, às vezes dramaticamente prolongados, podem se manifestar muito precocemente, na vida neonatal ou, só tardiamente, no período escolar. Os trabalhos clínicos vêm fomentando gradativamente o conhecimento científico em obstetrícia, com informações preciosas e úteis para o estabelecimento de diretrizes para a adoção de uma correta postura frente a casos mais complexos. Nesse sentido, Ferrazzi et al., $2002^{3}$, selecionaram, do seguimento longitudinal de 76 casos com restrição do crescimento fetal (RCF), 26 gestações de muita gravidade caracterizadas por: internação antes de 32 semanas, circunferência abdominal fetal abaixo do percentil dois, doppler umbilical (AU) com valores do índice de pulsatilidade (IP) acima de dois desvios padrão, $S / D$ de artérias uterinas (UT) acima de dois desvios padrão e interrupção da gestação por indicação fetal (por alterações na cardiotocografia) entre 26 e 34 semanas. Lembrando que as alterações no doppler AU e UT eram critérios de inclusão, e tendo por base a seqüência temporal das alterações ocorridas nos exames de doppler, antes do parto, classificam-nas em dois estágios: precoce e tardia. Foram categorizadas no estágio precoce: IP da artéria cerebral média e depois, diástole zero (DZ) no doppler $\mathrm{AU}$ as quais ocorrem em $50 \%$ dos casos em 16 e 15 dias respectivamente, antes do nascimento. No estágio tardio, aparecem em seqüência: alterações no doppler do ducto venoso (DV), diástole reversa (DR) no doppler $A U$, diminuição do pico de velocidade na artéria pulmonar, ducto venoso com onda a reversa e finalmente, diminuição do pico de velocidade na aorta. Essas alterações começam a aparecer, tardiamente, apenas a seis dias do parto. No seguimento pós-natal, aos seis meses, sobreviveram 14 crianças, sendo quatro com lesões neurológicas graves.

\section{Comentário}

Muito pertinentes os resultados obtidos pelos autores em apreço, pois corroboram com trabalhos mais recentes, incluindo os nacionais, os quais enfatizam a importância das alterações no doppler do DV. Tais alterações têm assumido papel de suma importância na conduçãa dos casos que evoluem com insuficiência placentária grave (DZ e DR). Como novidade, incluem a avaliação do fluxo central (pico de velocidade na artéria pulmonar e na aorta). São também relevantes a associação do bom prognóstico neonatal com 0 nascimento no estágio precoce e o pior prognóstico quando presentes as alterações do estágio tardio. Além de sua imprescindível colaboração para os procedimentos intervencionistas, o conhecimento da sequiência de alterações dopplervelocimétricas na circulação central e periférica fetal está em congruência com as recomendações modernas no atendimento médico, ou seja, o respeito à autonomia da paciente. Quanto mais precisas forem as informações, certamente, as decisões serão mais acertadas.

Seizo Miyadahira

Rosel Mieko Yamamoto Nomura

Marcelo Zugaib
Referências

I. Creasy RK, Barret C, Sweet M. Experimental intra-uterine growth retardation in the sheep. Am J Obstet Gynecol 1972; I 2:566-73.

2. ACOG. Utility of antepartum umbilical artery Doppler velocimetry in intrauterine growth restriction. American College of Obstetricians and Gynecologists. Committee Opinion; 1997. N. 188.

3. Ferrazzi E, Bozzo M, Rigano S, Bellotti M, Morabito A, Pardi Getal. Temporal sequence of abnormal Doppler changes in the peripheral and central circulatory systems of the severely growth-restricted fetus. Ultrasound Obstet Gynecol 2002; 19:140-6.

\section{Pediatria \\ MÉTODOS DE PREVENÇÃO OU TRATAMENTO DAS ALTERAÇÕES ESTRUTURAIS PULMONARES DECORRENTES DA HÉRNIA DIAFRAGMÁTICA CONGÊNITA}

Osíndices de mortalidade de recém-nascidos com hérnia diafragmática póstero-lateral de Boshdalek persistem altos, a despeito dos últimos avanços nos cuidados intensivos neo-natais. As alterações do desenvolvimento estrutural pulmonar decorrentes da compressão mecânica que as vísceras abdominais, em posição intratorácica, exercem sobre os pulmões durante o desenvolvimento fetal são responsáveis pelo óbito. Desta forma, pulmões de recémnascidos com hérnia diafragmática podem apresentar hipoplasia, espessamento da parede das arteríolas e deficiência de substância surfactante. Tais alterações causam hipertensão pulmonar, com persistência do padrão fetal de circulação, "shunt" direita-esquerda através do canal arterial e forame oval inter-atrial, além de redução da complacência pulmonar. Adicionalmente, são descritas alterações no sistema de fibras elásticas e do colágeno que podem ser responsáveis pela menor elasticidade do parênquima pulmonar ${ }^{1,2}$. Por fim, em modelos experimentais de hérnia diafragmática congênita descrevem-se alterações cardíacas, representadas por hipoplasia de ventrículo esquerdo e aumento do calibre do canal arterial ${ }^{3}$. 